\title{
Role of Electronic Factor in Soot Oxidation Process Over Tunnelled and Layered Potassium Iron Oxide Catalysts
}

\author{
P. Legutko • P. Stelmachowski • M. Trębala • \\ Z. Sojka $\cdot$ A. Kotarba
}

Published online: 26 February 2013

(c) The Author(s) 2013. This article is published with open access at Springerlink.com

\begin{abstract}
This paper describes the investigations of the catalytic activity in soot oxidation over well-defined iron oxide based materials. The nanostructuration of iron oxide by potassium into tunnelled $\left(\mathrm{KFeO}_{2}\right)$ and layered $\left(\mathrm{K}_{2} \mathrm{Fe}_{22} \mathrm{O}_{34}\right)$ ferrites and the surface promotion with $\mathrm{CeO}_{2}$ results in the marked increase in the catalytic activity (decrease of the ignition temperature down to $210^{\circ} \mathrm{C}$ and $T_{10 \%}$ to $310{ }^{\circ} \mathrm{C}$ ). The measurements of the catalysts work function showed that both nanostructuration and surface promotion with ceria of the best $\mathrm{KFeO}_{2}$ phase led to increase of the electron availability (decrease of the work function). Strong correlation of the catalytic activity in soot combustion of the $\mathrm{Ce}-\mathrm{K}-\mathrm{Fe}-\mathrm{O}$ systems with the work function value was revealed for the first time in the model studies, and can be used as a guideline for optimisation of the real catalytic filters.
\end{abstract}

Keywords Iron oxide - Potassium - Cerium oxide - Soot · Diesel $\cdot$ Oxidation $\cdot$ Promotion $\cdot$ Ferrite $\cdot$ Work function

\section{Introduction}

Soot particles emitted from diesel engines, due to their submicron size and specific chemical composition, are among the most hazardous urban air pollutants [1]. Native soot self-ignites at temperatures higher than $550{ }^{\circ} \mathrm{C}$, but it

Dedicated to Professor Adam Bielański on his 100th birthday.

P. Legutko · P. Stelmachowski $\cdot$ M. Trębala $\cdot$ Z. Sojka ·

A. Kotarba $(\bowtie)$

Faculty of Chemistry, Jagiellonian University, ul. Ingardena 3, 30-060 Kraków, Poland

e-mail: kotarba@chemia.uj.edu.pl could be burned in catalytic filters already at the temperature of the exhaust gases $\left(200-400{ }^{\circ} \mathrm{C}\right)$, provided an efficient catalyst is applied. The desired catalyst should not only assure complete combustion at relatively low temperatures, but also be cheap and stable at broad range of operating conditions. Facile washcoating and the use of ecologically benign raw materials are another practical requirements. In addition to catalyst developments, several approaches have been adopted in the field of soot filtration [2] and filter regeneration [3], as they may affect the desired morphology of the catalyst.

A large number of catalytic formulations, including single and mixed transition metal oxides, perovskite- and spinel-type oxides, and low melting point compounds, have been tested for the catalytic combustion of diesel soot [4-7]. Despite of the progress made, the reaction mechanism for this process has been scarcely addressed and therefore a lot of work is still needed in order to understand and advance a rational catalyst design. The investigated catalytic systems operate satisfactory only above $500{ }^{\circ} \mathrm{C}$, but upon impregnation with alkali, among which potassium [5, 8] is the most extensively investigated, their activity can be substantially enhanced [9]. Its positive role on soot combustion has been discussed in terms of: (i) an electron donor effect, increasing the oxygen reactivity; (ii) autogenic formation of low melting point compounds, or eutectics with other components of the catalyst, wetting the soot surface to increase the contact with the catalyst, (iii) the formation of a superficial carbonate intermediate and (iv) nanostructurization of the parent oxide. The latter case is may be illustrated by the transformation of $\mathrm{Fe}_{2} \mathrm{O}_{3}$ into tunnelled and layered ferrites of $\mathrm{KFeO}_{2}$, and $\mathrm{K}_{2} \mathrm{Fe}_{22} \mathrm{O}_{34}$ structures. Such materials exhibiting low work function and semiconductivity are promising generic materials for model redox catalytic 
studies since electronic properties can be easily tuned by Fermi level adjustment [10].

On the other hand $\mathrm{CeO}_{2}$ alone or in combination with other metal oxides can be also highly active in oxidation of soot and it is suggested that the mechanism involved in such a case is based of the redox properties of ceria related to its ability to deliver the structural oxygen for the reaction [11].

In the present work we described the nanostructuration of iron oxide into layered and tunneled $\mathrm{K}-\mathrm{Fe}-\mathrm{O}$ catalyst. The catalytic of the resultant ferrites can be further enhanced by doping with ceria nanoparticles. Both effects were discussed in terms of electronic factor-structureactivity relationship.

\section{Experimental Part}

Several iron containing oxides were used in the study: $\alpha-\mathrm{Fe}_{2} \mathrm{O}_{3}, \mathrm{~K}_{2} \mathrm{Fe}_{22} \mathrm{O}_{34}$ as well as promoted and unpromoted $\mathrm{KFeO}_{2} \cdot \alpha-\mathrm{Fe}_{2} \mathrm{O}_{3}$ was obtained from Merck and used without further processing. The samples of $\mathrm{K}_{2} \mathrm{Fe}_{22} \mathrm{O}_{34}$ ferrite were prepared by solid-state reaction of a stoichiometric mixture of $\mathrm{K}_{2} \mathrm{CO}_{3}$ with $\alpha-\mathrm{Fe}_{2} \mathrm{O}_{3}$ at $1200{ }^{\circ} \mathrm{C}$ as described previously [12]. The $\mathrm{KFeO}_{2}$ sample was synthesized from $\mathrm{K}_{2} \mathrm{CO}_{3}$ with $\alpha-\mathrm{Fe}_{2} \mathrm{O}_{3}$ according to the procedure described in [13]. In brief, the mixtures of finely ground powders were placed in a porcelain crucible and heated with the rate of $5{ }^{\circ} \mathrm{C} / \mathrm{min}$ in static air up to the final temperatures of $800{ }^{\circ} \mathrm{C}$ for $\mathrm{KFeO}_{2}$ and $1200{ }^{\circ} \mathrm{C}$ for $\mathrm{K}_{2} \mathrm{Fe}_{22} \mathrm{O}_{34}$. For $0.5-4 \mathrm{wt} \%$ Ce-doped $\mathrm{KFeO}_{2}$ samples, the appropriate fraction of $\alpha-\mathrm{Fe}_{2} \mathrm{O}_{3}$ powder was replaced by $\mathrm{CeO}_{2}$. Four $\mathrm{CeO}_{2}$ types of precursors were used for $\mathrm{KFeO}_{2}$ promotion: micrometric commercial cerium(IV) oxide (Merck), nanometric $\mathrm{CeO}_{2}$ obtained by solgel method, solid ammonium cerium(IV) nitrate (Merck) forming an oxide upon calcination and ammonium cerium(IV) nitrate water solution with subsequent impregnation of $\mathrm{KFeO}_{2}$, drying in $100{ }^{\circ} \mathrm{C}$ for $1 \mathrm{~h}$ and calcination in $400{ }^{\circ} \mathrm{C}$ for $4 \mathrm{~h}$. All such obtained samples were mixed with carbon black, Printex 80 (Degussa AG) with catalyst to soot ratios: $1 / 1,4 / 1,8 / 1$. Both "loose" than a "tight" conditions [14] were tested in preliminary experiments, but since the results were better reproducible in the latter conditions the "tight contact" was applied in the comparative tests. Catalytic activity of the samples was determined by temperatureprogrammed oxidation (TPO) tests, carried out with the catalyst/soot mixtures as described above. The amount of sample loaded into the reactor varied from 50 to $100 \mathrm{mg}$. The soot combustion experiments were carried using a heating rate of $10{ }^{\circ} \mathrm{C} / \mathrm{min}$, in the flow of $5 \% \mathrm{O}_{2}$ in He. The gas phase composition $\left(\mathrm{O}_{2}, \mathrm{CO}, \mathrm{CO}_{2}, \mathrm{H}_{2} \mathrm{O}\right)$ was monitored by the QMS spectrometer (SRS RGA200). The ignition temperatures were determined with the use of the Arrheniuslike plot ( $\ln X$ vs. $1 / T)$, which gives rise to a sharp turning point defining the start of the oxidation process in a nonarbitrary way in contrast to more subjective yet commonly use method of $T_{5} \%$ or $T_{10} \%$.

The samples were characterized by X-ray diffraction (XRD) (X'pert Pro Philips) for phase composition, SEM (Philips XL 30 ESEM) for grain size morphology, $\mathrm{N}_{2}$-BET (Quantasorb Jr) and XPS (Prevac/VG SCIENTA R3000) for surface area and composition, and Kelvin Probe (McAllister KP6500) for evaluation of electronic properties. The contact potential difference $\left(V_{\mathrm{CPD}}\right)$ measurements were carried out by the dynamic condenser method of Kelvin. To standardize the catalyst surface the measurements were carried out in vacuum of $10^{-7}$ mbar after annealing the sample to $400{ }^{\circ} \mathrm{C}$. The work function values were obtained from a simple relation e $\cdot V_{\mathrm{CPD}}=\Phi_{\text {reference }}$ $\Phi_{\text {sample }}$, using a standard stainless steel plate as a reference electrode $\left(d=3 \mathrm{~mm}, \Phi_{\text {reference }}=4.1 \mathrm{eV}\right)$.

\section{Results and Discussion}

Typical XRD patterns and the corresponding SEM images of the obtained ferrites are shown in Fig. 1. The diffraction
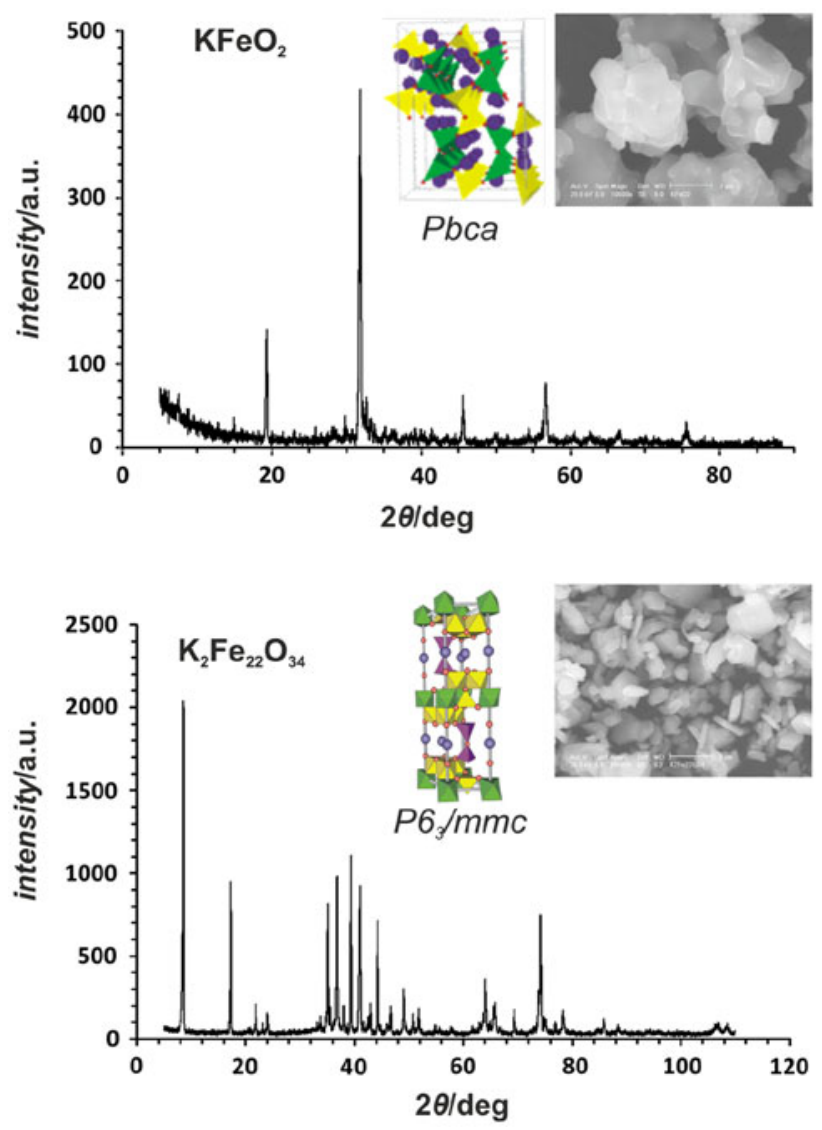

Fig. 1 The tunnelled $\left(\mathrm{KFeO}_{2}\right)$ and layered $\left(\mathrm{K}_{2} \mathrm{Fe}_{22} \mathrm{O}_{34}\right)$ structures of the generic potassium ferrites and the corresponding XRD patterns and SEM morphologies 


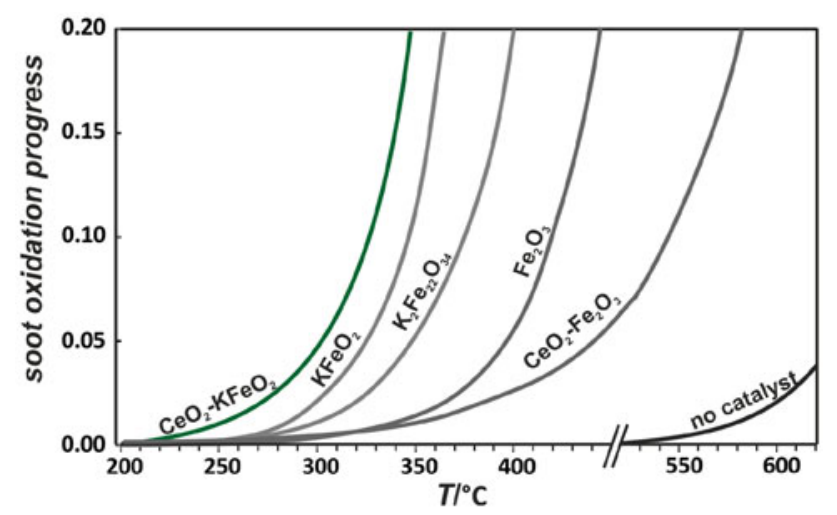

Fig. 2 Comparison of temperature-programmed oxidation of soot on several iron oxide based catalysts systems showing the synergetic effect of iron oxide promotion by potassium and ceria

revealed that the obtained samples of $\mathrm{KFeO}_{2}$ (indexed within Pbca-JCPDS-ICDD-39-0892 databases as reference) and $\mathrm{K}_{2} \mathrm{Fe}_{22} \mathrm{O}_{34}\left(P 6_{3} / m m c\right.$-JCPDS-ICDD 31-1034) were virtually monophasic. The $\mathrm{K}_{2} \mathrm{Fe}_{22} \mathrm{O}_{34}$ has the hexagonal layered structure and can be considered to be built up from spinel blocks of $\gamma-\mathrm{Fe}_{2} \mathrm{O}_{3}$ and separated by conducting potassium layers. The $\mathrm{KFeO}_{2}$ exhibits a tetragonal tunneled structure, that is not congruent with parent $\gamma-\mathrm{Fe}_{2} \mathrm{O}_{3}$. Since this ferrite has no layer structure, $\mathrm{K}, \mathrm{Fe}$, and $\mathrm{O}$ constituents are spatially more uniformly distributed (Fig. 1).

The introduction of ceria (at the level of $2 \%$ ) did not lead to any appreciable changes in the diffraction pattern. The SEM images of the bare ferrites reveal different morphologies of the $\mathrm{KFeO}_{2}$ and $\mathrm{K}_{2} \mathrm{Fe}_{22} \mathrm{O}_{34}$ grains (Fig. 1). Whereas for the $\mathrm{KFeO}_{2}$ crystallites of 3-5 $\mu \mathrm{m}$ are interconnected forming coarse blunt aggregates of about $10 \mu \mathrm{m}$, in the case of $\mathrm{K}_{2} \mathrm{Fe}_{22} \mathrm{O}_{34}$ the hexagonal well-shaped crystallites of

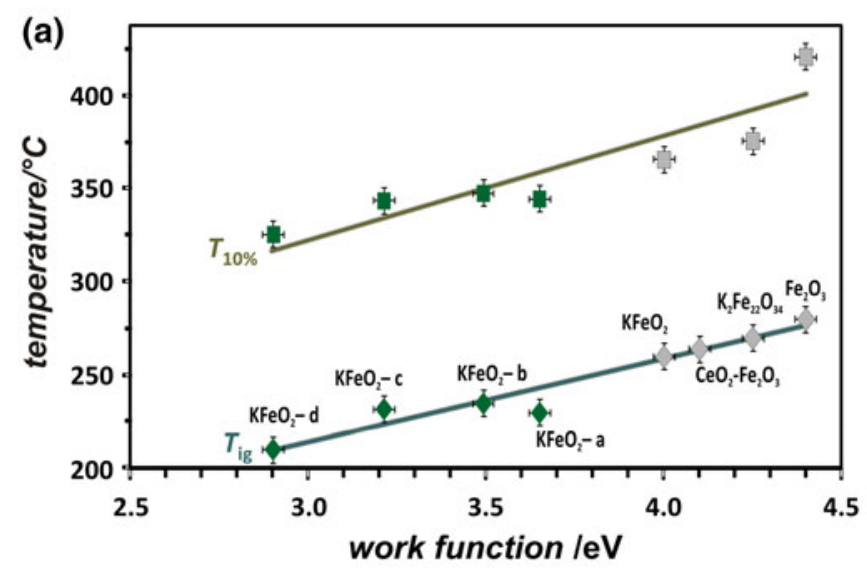

Fig. 3 The correlation of catalytic activity (ignition and $10 \%$ conversion temperatures) and electronic properties (work function) for the investigated iron oxide catalysts undoped and doped with $2 \%$
$0.5-2 \mu \mathrm{m}$ in diameter and thickness of $\sim 0.2 \mu \mathrm{m}$ were observed, and resembled that of a single $\mathrm{K}^{+}-\beta$-ferrite with stoichiometric composition [12]. The EDX analysis showed that the distributions of $\mathrm{K}$ and $\mathrm{Fe}$ are strongly correlated as expected for the ferrite phases, whereas ceria segregates at the surface in the form of spherical smaller nanocrystals with the size in the range of 10-500 $\mathrm{nm}$, depending on the applied preparation method. The XPS surface composition of the investigated samples indicated that within the surface layer only the constituent elements were found with the diagnostic binding energies for $\mathrm{KFeO}_{2}\left(\mathrm{BE}_{\mathrm{Fe} 2 \mathrm{p} 3 / 2}=709.7-710.0 \mathrm{eV}\right.$, $\left.\mathrm{BE}_{\mathrm{K} 2 \mathrm{p} 3 / 2}=292.2-292.4 \mathrm{eV}, \quad \mathrm{BE}_{\mathrm{O} 1 \mathrm{~s}}=530.4-530.8 \mathrm{eV}\right)$ and $\mathrm{K}_{2} \mathrm{Fe}_{22} \mathrm{O}_{34}\left(\mathrm{BE}_{\mathrm{Fe} 2 \mathrm{p} 3 / 2}=710.2-710.4 \mathrm{eV}, \mathrm{BE}_{\mathrm{K} 2 \mathrm{p} 3 / 2}=\right.$ 294.4-294.5 eV, BE $\left.\mathrm{O} 1 \mathrm{~s}_{5} 529.4-529.5 \mathrm{eV}\right)$. Small concentration of $\mathrm{CeO}_{2}$ combined with the overlapping Fe LMM Auger signal made it impossible to determine the $\mathrm{Ce} 3 \mathrm{~d}$ binding energies.

The comparison of the soot combustion activity of the several investigated catalysts as a function of temperature is presented in Fig. 2. The synergetic effect of nanostructuration of iron oxide by potassium into tunneled $\mathrm{KFeO}_{2}$ and layered $\mathrm{K}_{2} \mathrm{Fe}_{22} \mathrm{O}_{34}$ and the surface doping with ceria can be clearly noticed. The transformation of iron oxide into ferrites by potassium addition lowers the light off temperature by about 70 and $100{ }^{\circ} \mathrm{C}$ for $\mathrm{K}_{2} \mathrm{Fe}_{22} \mathrm{O}_{34}$ and $\mathrm{KFeO}_{2}$, respectively. Yet, the reactivity of the most active phase $\mathrm{KFeO}_{2}$ can be further enhanced by $\sim 30{ }^{\circ} \mathrm{C}$ upon the $2 \% \mathrm{CeO}_{2}$ addition (Fig. 3, green points). In order to check the stability of the best material the 10 consecutive tests of soot oxidation were performed for the series of $\mathrm{CeO}_{2}$ $\mathrm{KFeO}_{2}$ catalysts (at each time a new portion of soot was added to the same catalyst at the same ratio of 8/1). The results revealed that the sustainable activity was maintained within the experimental limit (the standard deviation of $T_{\text {ig }}<8.5^{\circ} \mathrm{C}$ ).

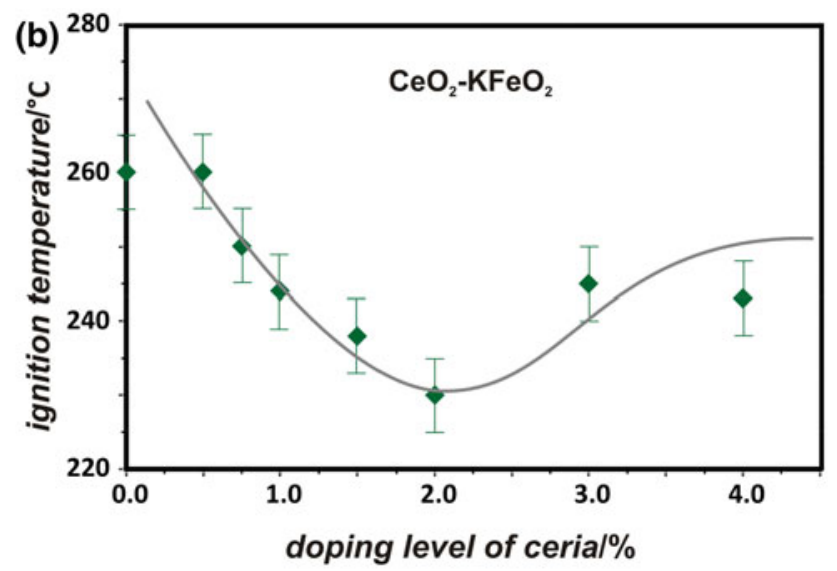

of ceria (a). The effect of doping level of ceria on soot oxidation activity of $\mathrm{KFeO}_{2}$ with the optimal content of ceria at $2 \%$ (b) 
It is worth mentioning that for the whole series of the investigated samples a strong correlation of the catalytic activity gauged by both the ignition $\left(T_{\mathrm{ig}}\right)$ and $10 \%$ conversion $\left(T_{10} \%\right)$ temperatures of soot combustion with the work function value exists (Fig. 3a). The observed correlations reveal that the electronic effect (availability of electrons for oxygen activation) governs the soot combustion process. It is valid with the same spectacular trend either in the case of nanostructuration of iron oxide by potassium (gray points) and for subsequent surface modification of the best performing $\mathrm{KFeO}_{2}$ ferrite by $2 \%$ of $\mathrm{CeO}_{2}$ (green points). Such level of doping was found to be optimal, as it can be inferred from the Fig. 3b. The characteristic Topping-like behavior confirms that the observed changes of $T_{\text {ig }}$ can actually account for by the associated work function changes. As a result, those findings show that the unique, concise parameter-the catalyst work function-plays the key role in the soot combustion process. The observations of a prime importance of catalyst work function modification for the activity was also observed for other redox reactions $[15,16]$.

As mentioned, the electronic promotion effect on soot combustion can be explained in terms of enhanced energetic accessibility of the electrons for activation of the dioxygen molecule by the catalyst. Indeed, the facilitation of the electron transfer from the catalyst surface to $\mathrm{O}_{2}$ molecules gives rise to the formation of strongly reactive surface oxygen species, such as $\mathrm{O}_{\mathrm{x}}^{-}$radicals $\left(\mathrm{O}^{-}\right.$and $\left.\mathrm{O}_{2}{ }^{-}\right)$, which are known as efficient soot oxidation agents taken into account in kinetic modeling of soot oxidation [17]. It is well known that the work function controls the nature of surface oxygen speciation. Two main scenarios related to dioxygen chemisorption include singly ionized molecular $\left(\mathrm{O}_{2}{ }^{-}\right)$and atomic $\left(\mathrm{O}^{-}\right)$species as revealed elsewhere [18]. Nonetheless, at this stage the established quantitative work function-combustion temperature relationship can be used as a guidelining principle for the optimization of the catalyst for soot combustion, and searching for new promising washcoats of DPF filters.

\section{Conclusions}

Strong correlation of the catalytic activity of the $\mathrm{Ce}-\mathrm{K}-\mathrm{Fe}-$ $\mathrm{O}$ systems (ignition and $10 \%$ conversion temperatures of soot combustion) with the catalyst work function value was revealed for the first time. The nanostructuration of iron oxide by potassium into tunnelled $\left(\mathrm{KFeO}_{2}\right)$ and layered
$\left(\mathrm{K}_{2} \mathrm{Fe}_{22} \mathrm{O}_{34}\right)$ ferrites, together with the surface promotion by ceria can be interpreted in the unique term of the electronic promotion, gauged by the work function lowering. It is proposed that the enhanced electron availability is beneficial for the generation of the surface reactive oxygen species, initializing the soot combustion process. The established correlation was used as a guideline for systematic optimization of the $\mathrm{KFeO}_{2}$ catalysts by ceria resulting in soot ignition temperature of $210^{\circ} \mathrm{C}$.

Acknowledgments This study was sponsored by National Science Centre Polish Grant number 2011/01/B/ST4/00574.

Open Access This article is distributed under the terms of the Creative Commons Attribution License which permits any use, distribution, and reproduction in any medium, provided the original author(s) and the source are credited.

\section{References}

1. van Setten BAAL, Makkee M, Moulijn JA (2001) Catal Rev 43:489

2. Bensaid S, Marchisio DL, Russo N, Fino D (2009) Catal Today 147S:S295

3. Bensaid S, Fino D (2011) Catal Today 176:417

4. Fino D (2007) Sci Technol Adv Mater 8:93

5. Ura B, Trawczyński J, Kotarba A, Bieniasz W, Illan-Gomez MJ, Bueno-Lopez A, Lopez-Suarez FE (2011) Appl Catal B Environ 101:169

6. Fino D, Russo N, Saracco G, Specchia V (2008) Powder Technol 180:74

7. Azambre B, Collura S, Darcy P, Trichard JM, Da Costa P, Garcia-Garcia A, Bueno-Lopez A (2011) Fuel Process Technol 92:363

8. Nejar N, Illán-Gómez MJ (2007) Appl Catal B Environ 70:261

9. An H, McGinn PJ (2006) Appl Catal B 62:46

10. Bieniasz W, Trebala M, Sojka Z, Kotarba A (2010) Catal Today $154: 224$

11. Krishna K, Bueno-Lopez A, Makkee M, Moulijn JA (2007) Appl Catal B Environ 75:189

12. Ito S, Kurosawa H, Akashi K, Michiue Y, Watanabe M (1996) Solid State Ionics 86:745

13. Kotarba A, Barański A, Hodorowicz S, Sokołowski J, Szytuła A, Holmlid L (2000) Catal Lett 67:129

14. Neeft JPA, van Pruissen OP, Makkee M, Moulijn JA (1997) Appl Catal B Environ 12:21

15. Maniak G, Stelmachowski P, Zasada F, Piskorz W, Kotarba A, Sojka Z (2011) Catal Today 176:369

16. Kotarba A, Adamski G, Piskorz W, Sojka Z, Sayag C, DjegaMariadassou G (2004) J Phys Chem B 108:2885

17. Gross MS, Sánchez BS, Querini CA (2011) Chem Eng J 168:413

18. Yamawaki M, Bak T, Nowotny MK, Nowotny J, Sorrell CC (2005) J Phys Chem Solids 66:322 